\title{
Reading the Local Context: \\ A Causal Chain Approach to Social Accountability
}

\section{Anuradha Joshi}

\begin{abstract}
There is a general consensus that 'context' matters for development outcomes, yet we have little understanding of how exactly 'context' affects outcomes. This article focuses on the question of 'context' in social accountability (SA) initiatives by separating macro- and micro-contextual factors. On the macro side (country level), accountability processes need to take into account broad factors such as national histories of citizen-state engagement. On the micro side, local factors can drive the extent to which SA initiatives are successful, even within otherwise broadly similar national contexts. The article outlines the basic components of accountability and proposes a 'causal chain' strategy to better understand the micro-context. This would allow existing evidence to be reorganised to assess the promise of existing and new initiatives by deconstructing the various mini-causal pathways (i.e. in the micro-context) and understanding the contextual conditions that make them work.
\end{abstract}

\section{Introduction}

A common refrain in eliciting lessons from experiences with development initiatives is that the outcomes depend critically on 'context' (Booth 2011). This is also true of the range of recent social accountability (SA) initiatives that are increasingly popular among donors and civil society organisations (Ringold et al. 2012; McGee and Gaventa 2011; Foresti, O’Neil and Hudson 2007)..$^{\prime}$ Despite this general consensus, there is limited progress on understanding exactly how 'context' affects outcomes; and the related question of exactly which contextual factors matter. Dictionary definitions of context help illustrate the problem: 'the conditions and circumstances that are relevant to the event or fact' (Free Dictionary); 'the general situation within which something happens that helps to explain it' (Macmillan); 'the circumstances that form the setting for an event, statement, or idea, and in terms of which it can be fully understood' (Oxford English Dictionary). ${ }^{4}$ The ambiguity in these definitions lies in the fact that which 'circumstances', 'conditions' and 'general situation' are relevant to the event is subjective. So how can we get a handle on which elements of context are relevant to understanding success and failure?
In this article, drawing on the large and growing reported experience with local social accountability processes, I suggest that there are two broad parts to the issue - the macro and the micro. On the macro side, there is now increasing acknowledgement that accountability processes are better viewed as located within larger histories of citizen-state engagement and related political processes (Fox 2007; Joshi and Houtzager 2012). This recognition has led scholars to identify broad features of the context that seem to matter for outcomes. The macro approach, which has dominated the limited existing literature, largely focuses on particular socioeconomic and political realities at the country level. What we have learned to date from this approach is elaborated briefly in Section 2 following this introduction.

At the micro level, local factors can clearly drive the way certain SA initiatives unfold and the extent to which they are successful even within otherwise broadly similar contexts. For example, very similar initiatives intended to provide information to communities in order to support accountability demands and improve educational outcomes could have different impacts despite being in similar country contexts (Pandey, Goyal 
and Sundararaman 2009). Yet, few have explored why this might be the case and how one might approach issues of context at the local level. The main contribution of this article is an elaboration of the individual components of social accountability at the local level, and a 'theory of change or causal chain' strategy to gain traction on the thorny issue of micro-context. Such a strategy is elaborated in Section 3. The argument is that two broad aspects are important in understanding the micro-context: (a) the features of the individual components of accountability processes and (b) the causal chains through which social accountability processes linking these broad components are expected to work. The disaggregation of components of information, citizen action and state response is carried out in Section 4. A preliminary relatively linear causal chain is mapped in Section 5, which could be used as a potentially basic frame on which complex chains could be developed. The conclusions, presented in Section 6, map out the implications of this approach to context.

\section{The macro-context: broad political economy features}

Over the years, there have been several attempts to systematically understand the larger contextual factors that influence the outcomes of development initiatives under various frameworks such as the 'drivers of change' approach, or more recently political economy analysis (PEA) and power analysis (PA) (Pettit and Mejía Acosta, this IDS Bulletin). The idea is to identify factors that are enabling or constraining with respect to change, given the particularities of socioeconomic and political conditions in a country or context (Routley and Hulme 2013). Driven by the unpredictability of outcomes of similar developmental initiatives in different contexts, the drivers of change/political economy approach attempts to expose the underlying power relationships, incentives and interests among broad groups that might affect whether specific reforms will have traction in specific contexts. A recent definition of PEA crystallises the thinking behind these approaches:

$[\mathrm{P}]$ olitical economy analysis investigates how political and economic processes interact in a given society, and support or impede the ability to solve development problems that require collective action. It takes particular account of the interests and incentives driving the behaviour of different groups and individuals, the distribution of power and wealth between them, and how these relationships are created, sustained and transformed over time

(Unsworth and Williams 2011).

Practical toolkits have been developed by several organisations as a guide for undertaking PEA (Fritz, Kaiser and Levy 2009; DFID 2009). These toolkits contain several guiding questions about contextual features in different aspects of analysis (e.g. the business-state relationship, state dependence on earned revenues, etc.). Some thinking has also gone into developing guides to PEA in particular sectors (Moncrieffe and Luttrell 2005; EC/Europeaid 2008; Reich and Balarajan 2012).

In the field of social accountability, such macrocontextual analysis is relatively new. Although country-level contextual analysis for social accountability, not surprisingly, shares many features with general PEA, it also tends to focus on particular features; for example, freedom of media, as they are directly related to SA initiatives. Further, studies have sought to identify factors that run across instances of success (Bukenya, Hickey and King 2012; Bukenya and King 2012; McGee and Gaventa 2011; Joshi 2013). Some of the common lessons include: (1) that information and transparency is necessary but not sufficient for accountability actions to be undertaken; (2) that accountability action without a corresponding capacity for state response can be counterproductive; (3) that effective sanctions play an important role in sustaining accountability demands; (4) that collective action is important for accountability to the poor; and (5) that existing cases of successful social accountability are underpinned by cross-boundary alliances between social actors and state reformists that create accountability coalitions.

O’Meally (2013) offers a recent, and relatively comprehensive review of the literature on contextual factors that matter for social accountability. Because this is one of the most recent attempts to provide a framework for analysing context, it is useful to go into it in some detail here. His take on contextual factors is explicitly political. The underlying metatheory of change that underpins successful social accountability and drives his contextual analysis is that: 
if pro-accountability and pro-poor networks in society are adequately resourced and build coalitions with pro-accountability networks and actors in political society through rounds of state-society bargaining and interaction; and,

if these coalitions are able to: (a) negotiate changes with anti-change actors; (b) generate sufficient counter-veiling power to change governing elite incentives and challenge the primary/secondary political settlement; and/or (c) active contextually legitimate accountability mechanisms...

...then, this might result in (a) coercion - a backlash from existing power-holders;

(b) co-optation and collaboration incremental improvements in accountability relations and developmental gains within the existing political settlement; and/or (c) change - more fundamental change, to differing degrees, leading to the formation of a 'new' political settlement/social contract (O'Meally 2013: 29-30).

It is clear from this very broad theory of change, that the contextual conditions that matter range from the deep-rooted structures in society, for example, political settlements, to more tractable features, for example, the nature of civil society organisations. Capturing the range of factors that might be included in such analysis is vast and O'Meally identifies six broad 'contextual domains': (a) civil society, (b) political society, (c) inter-elite relations and the political settlement; (d) state-society relations and the social contract; (e) intra-society relations and issues of social inclusion; and (f) global factors. These are then further broken down into various aspects that have a bearing on their enabling or constraining potential.

The characteristics of these domains in particular contexts can point to the feasibility of social accountability as a specific strategy for improving services, empowering citizens and strengthening governance. The main messages from O'Meally's (2013) review of context suggests that practitioners should think politically when considering social accountability, link social accountability strategies to prevailing institutions of political accountability, work to enhance state capacity to respond to generated demand, support pro-accountability coalitions that cut across the state-society divide, learn by doing and use longer time horizons, take account of global influences on accountability, build on existing processes and make issues of inclusion and exclusion more central to accountability processes. Some have undertaken further work to highlight the constraints and entry points for social accountability work in typified contexts, for example relatively closed polities (Gandhi, forthcoming) or fragile states (Boeckman 2012). While this work advances our thinking considerably on the features of context that seem to matter, these are still very broad messages and pose the challenge of how to operationalise them in particular local contexts.

\section{The micro-context: assumptions and causal chains}

While the contextual factors identified in the studies discussed above (particularly O'Meally 2013) are useful in providing key questions that practitioners should be asking about various domains in specific kinds of polities, they do not help in suggesting which particular strategies are likely to work. Rather they help identify whether SA as a general approach should be considered or not.

Yet, developmental actors require signposts of a more detailed kind. Are community scorecards more appropriate or are social audits better in specific contexts? Should collective action focus on pursuing rights claims through existing complaint mechanisms or should one organise street protests? Are information provision strategies likely to be successful, or is the creation of strong channels of grievance redress? What combinations of approaches work in specific settings? What potential bottlenecks are likely to emerge? What essential factors need to be in place before attempting particular strategies? While practitioners regularly take decisions on these kinds of questions, based on a range of factors, including their own capacity, past experience with approaches, and so forth, they could be better informed by a clearer understanding of the lessons from what initiatives have worked in the past, and in what contexts.

So how are we to make judgements of this kind from the evidence (limited as it is) that exists? We know from the literature that even lessons from the most highly regarded evaluation studies - randomised controlled trials (RCTs) - of social 
accountability interventions have problems with generalisability of the results (external validity) (Woolcock 2009; Ravallion 2009).

In fact, an insightful reflection highlights several issues with prevailing interpretations of the existing evidence to date, especially evidence of failure (Fox 2014). The most widely cited studies, rather than suggesting that social accountability does not work, actually point to some of the conditions that make it work. Foremost, in keeping with the wider literature, across the studies evidence shows that information alone is not enough to spark community action and subsequent provider response. One needs supporting processes for collective action. Similarly, neither is community monitoring from below enough to get service improvements; mainly because it lacks bite. Rather, combined with other accountability mechanisms (e.g. top down accountability, or sanctions with teeth), it can have the desired effects. Finally, elite capture is a real problem in community-focused programmes, including social accountability ones. Fox concludes from the evidence that we need to rethink some of our basic propositions of accountability work to move from a focus on 'tactical' approaches to more 'strategic' ones.

Given these challenges and the general problem of context posed by accountability work, in a recent paper Cartwright and Munro (2010), elaborate on the problem of external validity and outline two conditions that are important in extrapolating the causal inferences made in a particular study context to another: (a) the study and the target population are the same with respect to the probability of their relevant compositions; and (b) the study and target population are the same with respect to the causal laws for the outcomes. Yet, randomisation does not deal with the latter issue. In other words, the processes that make the mechanism work, may not be the same. To generalise we need to understand specific features of context. As they highlight:

Most causal and probabilistic relations relied on in health care and social practice are not fundamental: they do not just hold, they hold on account of some underlying structure that gives rise to them. When the structures are different, so too are the causal and probabilistic relations they create (Cartwright and Munro 2010: 261).
Thus, they point to the need for unpacking the initiatives in terms of a theory of change or causal chain, in order to understand how desired outcomes might work.

Increasingly, this approach to SA initiatives is being seen as a promising one (World Bank 2013; Vogel 2012; Tembo 2012; Lieberman, Posner and Tsai 2012; Holland and Thirkell 2009). In groundbreaking new work that parallels the approach of this article, the World Bank is elaborating on key elements of social accountability and the factors that drive them by re-examining the evidence we have from evaluation research, but also from behavioural economics, anthropology and political science which allows for testing links in implicit causal chains for their robustness (World Bank 2013; World Bank, forthcoming). A theory of change/causal chain approach allows one to understand implicit assumptions underlying particular activities, the conditions that are enabling or constraining as well the extent to which initiatives travel through the assumed causal chain and reach intermediate objectives even if the final outcomes are not those expected. This approach can, in particular, identify bottlenecks in the causal chain that can be responsible for some observed adverse outcomes.

In taking up the task of unpacking causal chains, we propose that two aspects are important to understand the potential of particular approaches in specific settings: the components of the pathway plus the mechanisms (and related microcontextual factors) through which each of the components could lead to the other. An analogy from the physical world might be useful here. Suppose we want to push an object from location A to B. We can use different mechanisms to do this - we could place wheels under the object and roll it to B; we could push it to location B, we could lift the object and place it at B. The mechanism in this example is the means we use to relocate the object. However, each of these mechanisms will operate dependent upon the specificities of the component (object) itself - the object may be lifted because it is light, or because it may be dismantled and carried piece by piece. It is also important to note that the actual enabling conditions might look different in different cases due to some micro-contextual ${ }^{5}$ conditions; for example, we can use wheels if the path to B is relatively smooth. Often we assume 


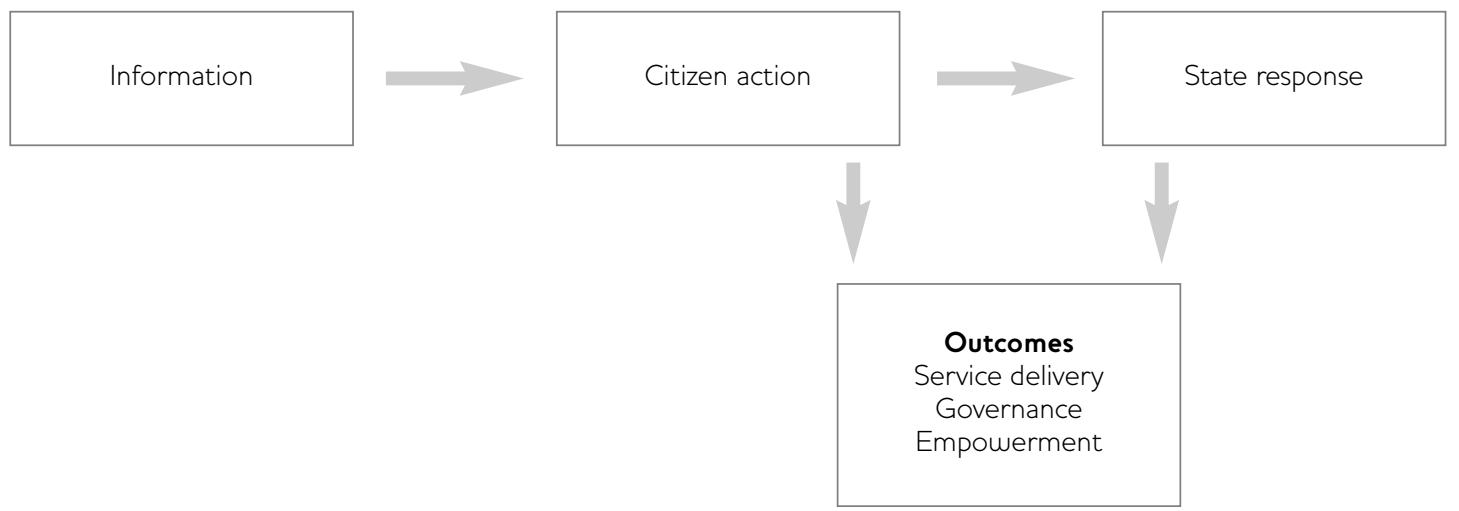

Source Author's own.

these conditions are in place because they seem ubiquitous in the cases where the intervention works and we would not pay attention to them. However, they underpin why some initiatives work, and may not be present in specific instances we are concerned with, and thus lead to intervention failure. Overall, the role the enabling micro-context plays is the same - in terms of enabling the mechanism to work. For any specific component, we need to understand both how the mechanism works and the microcontext/component in order to see whether particular strategies will help us reach the outcome we desire.

One additional consideration is necessary before beginning to unpack SA. One can take two different approaches to what one means by an SA 'intervention'. On the one hand, one can differentiate by common SA interventions - for example, community scorecards, social audits and so forth - and elaborate an evaluation framework and a theory of change for each. This has been the prevailing approach in several studies (Foresti et al. 2007; Barr et al. 2012). On the other hand, one might start from a more general broad theory of change that underpins ideas about demand for good governance and citizen-led accountability. This might comprise a series of steps that combine in different ways in common SA initiatives - for example, awareness raising, information demands, protests, etc. (Joshi and Houtzager 2012). Although less prevalent in the literature, I take this approach in the article for reasons that will become evident in the next section.

\section{Unpacking the accountability black box: information, citizen action and state response}

If one starts from the point of disaggregating social accountability into its component parts (rather than looking at 'labelled' interventions such as social audits, community monitoring, etc.), then as a first step one will have to separate its broad components. While this might be done in different ways (see World Bank, forthcoming), and will vary depending upon the nature of the citizen groups and the target of accountability actions among other things, we know that social accountability has something to do with three broad things: information, citizen action and state responses.

The conventional assumptions have been that the provision of some kind of information/ transparency will lead to citizen action, which will then together lead to state response (see Figure 1). This unidirectional causal chain often implicitly underpins SA initiatives.

However, the relationship between these three components is not so straightforward - each of the arrows, from information, to citizen action to state response, could work in the other direction (see Figure 2). For example, citizen action through mobilisation could lead to the generation or exposure of relevant information. State responses may encourage or restrain citizen action. State responses can also take the form of making previously opaque information public. And sometimes, the revelation of information can directly spur state responses without being mediated through citizen action. It seems clear that the linkages between these 


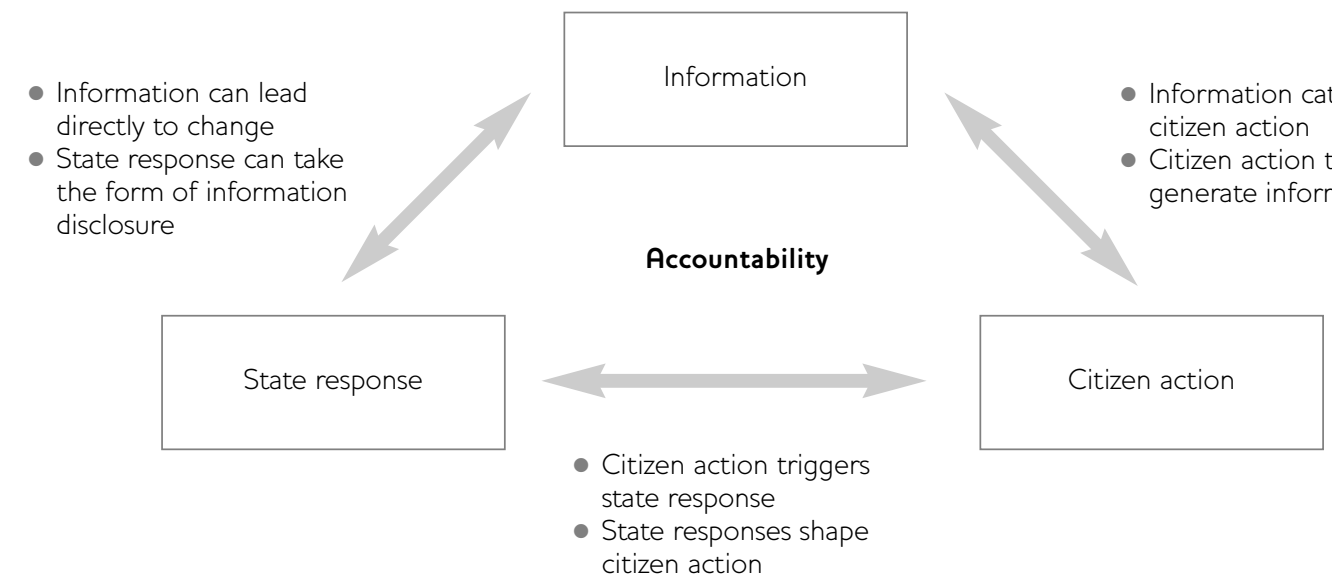

Source Author's own.

three components are not as straightforward as assumed in the unidirectional causal chain.

In addition to the complexity of the multiple pathways of interaction between these three components, the nature of the component itself matters. All information is not equal; all citizen action is not the same and all state responses cannot be seen as accountability enhancing. Although most scholars and practitioners, if questioned, would acknowledge the qualitative differences between different types of information, citizen action and state response, curiously the literature treats them all alike, especially when attempting to aggregate lessons on social accountability. This ambiguity calls for a closer conceptual look at the nature of each component of social accountability.

\subsection{Information}

There are several issues related to the nature of information in social accountability processes. First and foremost is the issue of usefulness: as Fox (2007) puts it, is the information opaque or clear? If the information is provided in a form that is not understandable or actionable then it is unlikely to trigger collective action (Fung, Graham and Weil 2007). Usually, whether information is opaque or transparent depends upon the source of the information, and the incentives people have for full and clear disclosure.

Second is the credibility of the information source - it is likely to be accurate and reliable? Does the information provider have incentives to distort or obfuscate information? If the information is produced through a process in which citizens have participated then it is more likely to be credible and legitimate. On the other hand, information provided by governments will be considered more authoritative when considering state responses. When the information used in accountability demands is generated through a process involving both providers and users, then it is likely to have more legitimacy for all stakeholders.

Third, there is the issue of whether the information provided is about official standards, (of either/both processes and outputs) or whether the information is about performance in relation to other similarly placed comparators. On the one hand, when the information relates to established standards, then citizens are expected to mobilise and demand performance up to the official standards, which may be unrealistic. On the other hand, when information is about performance and is comparative (e.g. lead tables in the UK), citizens may be provoked by realising that similarly placed groups are receiving better services than them for no rational reason. Here the trigger for collective action is competition among localities (or groups) based on more realistic expectations.

Fourth, information can have an inspirational effect. ${ }^{6}$ Stories of successful citizen action leading to greater state responsiveness and improved services elsewhere, can catalyse a 'we can do it too' spirit in communities that might otherwise 
not consider accountability demands. The lessons from success here are not so much the actual citizen action or pathways through which accountability gains were made, as much as the fact that it is possible to gain success in accountability claims at all, despite difficult environments.

These four aspects of information (and there might be others) imply different causal paths for usage as a part of the accountability process. Each potential pathway has a set of assumptions that underlie it. For example, there is no reason to believe that clear information from a noncredible source will trigger citizen demands for accountability. Or when information is about standards that are out of reach, there may be little faith in state responsiveness. Starting with categorising the nature of information on the four aspects can throw light about the possible paths that link information with both citizen action and state responses.

\subsection{Citizen action}

Similar to the discussion on information, the content of citizen action can be broken down into several elements (Joshi and Houtzager 2012). First, citizens can demand information from governments related to budgets and spending, processes, standards and performance. Often budgets and expenditures can be skewed towards the better off, processes and entitlements are not well understood, and the actual performance of government remains opaque. This is the reason why information campaigns often accompany SA initiatives.

Second, citizen action itself can generate relevant information - for example, through perception surveys, expenditure tracking or budget analysis. Such information, as discussed previously, is likely to be viewed more credibly by communities due to the legitimacy of its collation. Simultaneously, the process of demanding or gathering information, however, might itself spark off greater mobilisation for accountability.

Third, societal actors can keep a watch on services through ongoing monitoring of the actual quality of public goods being delivered. Are teachers absent from classes? Are medical supplies in stock? Are officials demanding bribes for services? Are contractors using appropriate materials as per specifications? These issues are best scrutinised by those who are close to the services in question and are able to monitor performance on a regular basis. Such ongoing monitoring forms part of accountability action, but need not require state response if nothing is found to be amiss.

Fourth, if monitoring and information gathering shows that there are gaps between expected and delivered levels of service, then further citizen action is required in terms of seeking accountability. Such action can involve making demands to enforce legal standards that are not currently being met, or explanations of why it is not feasible. For example, communities may demand more teachers in a school if the teacher pupil ratio is below that established by law. This is an important element of social accountability: to give governments opportunities to remedy the situation when suitably informed or provide credible explanations of why the standards cannot be met.

Finally, if dissatisfied with the explanations provided, or if corruption is exposed, social groups can seek grievance redress. This could be done either through existing administrative complaint mechanisms, political protests or litigation. If grievance redress channels do not exist, citizen action may take the form of demands for them to be established.

Which of the above actions are actually undertaken depends upon various factors including whether communities are mobilised, past experience of interactions with the state, and cultures of expectations from the state. In addition, these various actions can be combined in different ways in sequence, or in parallel. Underpinning each of these actions, is a set of assumptions about how these might work.

\subsection{State response}

Within the literature on social accountability, the least explored aspect is that of state response. While the key expectation is that public officials will respond to citizen action and make improvements, the actual substance of their response can vary considerably including generating and releasing information, to reforming processes, mobilising resources, advocating for reforms at higher levels and changing their own behaviour. They could also initiate investigations of wrongdoings and 


\begin{tabular}{|c|c|c|c|}
\hline Component & Content & Process & Assumptions/Micro-context \\
\hline Information & $\begin{array}{l}\text { Performance } \\
\text { - Compared to standards } \\
\text { - Compared to others } \\
\text { Inspirational }\end{array}$ & $\begin{array}{l}\text { Transparency } \\
\text { Generating new } \\
\text { information (e.g. perception } \\
\text { data, monitoring data) } \\
\text { Media campaigns }\end{array}$ & $\begin{array}{l}\text { Literacy/access } \\
\text { Legitimacy/credibility of } \\
\text { information }\end{array}$ \\
\hline Citizen action & $\begin{array}{l}\text { Demand information } \\
\text { Generate information } \\
\text { Monitor performance } \\
\text { Seek accountability } \\
\text { Seek grievance redress }\end{array}$ & $\begin{array}{l}\text { Formal bureaucracy } \\
\text { Protests } \\
\text { Political articulation } \\
\text { Formal complaint channels } \\
\text { Litigation }\end{array}$ & $\begin{array}{l}\text { Priorities } \\
\text { Belief in efficacy of channel } \\
\text { Sense of entitlements }\end{array}$ \\
\hline State response & $\begin{array}{l}\text { Release information } \\
\text { Reform processes } \\
\text { Increase resources } \\
\text { Demands at higher levels } \\
\text { Investigation/sanctions }\end{array}$ & $\begin{array}{l}\text { Transparency } \\
\text { Reduced corruption } \\
\text { Behaviour change } \\
\text { Formal and informal } \\
\text { channels of reform demands } \\
\text { Formal and informal } \\
\text { channels of enquiry and } \\
\text { punishment }\end{array}$ & $\begin{array}{l}\text { Legitimacy of grievance } \\
\text { Capacity } \\
\text { Public service motivations } \\
\text { Reputational concerns } \\
\text { Channels of influencing } \\
\text { higher levels }\end{array}$ \\
\hline
\end{tabular}

sanction those responsible. On the negative side, they could instigate reprisals and ignore reputational taints. What sorts of citizen action trigger particular responses, and in what contexts? While there is consensus that social accountability advocates should focus on state inclination and capacity to respond, there is little understanding of why officials might take certain actions rather than others (for an exception see Aiyar and Mehta 2014). Unpacking the assumptions we make in expecting state responses to citizen action will be key to understanding the micro-contextual factors that matter.

For each of the components: of information, citizen action and state response, there are associated processes depending upon the form components take. Information can be generated through crowd sourcing, perception surveys, participatory research or monitoring and be made public through a variety of channels, including the media. State responses can be in the form of behaviour changes, public sector reform, retaliation against claimants, and sanctions against those responsible. Each of these processes that circumscribe particular elements has an associated set of assumptions that underpin them which are illustrated in Table 1.

\section{Tracing causal chains}

In the previous section, we examined each component of the black box more carefully to understand its nature and sub-parts. In this section, we focus on the relationships between the components - the pathways through which each component is expected to lead to the others. In order to do this, we start by tracing causal chains, assuming rational, self-interested individuals. Further work might expand such causal chains based on advances in behavioural economics and social psychology that elaborate more realistically on patterns of human behaviour. ${ }^{7}$ In the following we examine an illustrative and the most common causal chain for social accountability - the pathway from information to state response although there are other equally valid pathways to accountability.

There is a widespread expectation that providing information to the poor and disadvantaged will spur them into demanding better services. In fact several interventions have been premised on such an assumption (Banerjee et al. 2010; Pandey et al. 2009; Khemani 2008). Yet many studies suggest that information has little or no effect (Bruns, Filmer and Patrinos 2011). Similarly, social accountability is based on the belief that citizen action leads to positive outcomes (service delivery, 


\section{Information quality (Characteristics of the information type)}

Is the information new and unexpected? $\checkmark$

Is the information understandable? $\checkmark$

Does the information highlight gaps in performance? (As compared to standards, expectations or comparators) Is the information widely publicised?

Is the information credible?

(Who has provided information, is it legitimate due to processes of generation?)

\section{Citizen action} (Unpack motivations)

Did I receive the information? $\checkmark$

Do I understand the information? $\checkmark$

Is the situation worse than expected?

$$
\checkmark
$$

Do I care?

$\checkmark$

Can I do anything about it?

Do I think my actions will have impact?

If I need others will they join?

\section{Collective action/strategy}

(Substantive characteristics of citizen demands)

Who is likely to be responsive?

What framing are they likely to listen to? (Moral appeals, legal obligations, humanitarian grounds, political stability)

Are there official channels where I/we could target my demands and complaints?

Is going to the courts likely to have an effect? $\checkmark$

Do l/we have the time and resources?

$$
\checkmark
$$

Are there other actors I could take joint action with?

\section{State response \\ (Substance of response types)}

Do I think citizens have legitimate grievances? $\checkmark$

Do I hold responsibility for the particular public good? $\checkmark$

Am I likely to be officially sanctioned due to citizen action?

Do I care about my reputation?

(If not, possibility of reprisal)

Do I care about the service?

$$
\checkmark
$$

Do I think I can do something about the situation? (If not, then could lead to helplessness) $\downarrow$

Do I have the capacity and resources to take action? (If not, then could lead to frustration)
Do I need others to contribute in terms of resources/reforms? $\checkmark$

Can I motivate others? Are others likely to collaborate?

Do I have access to higher levels?

(Depends upon whether resources, reformists are identifiable within the system)

Reforms/increased resources

\section{K}

I mproved services

\section{Additional potential outcomes}

Empowered communities

Increased trust between citizens and state actors Reduced corruption

Institutionalised channels for interaction

Responsive public officials

Increased legitimacy of the state

Source Adapted and expanded from Lieberman et al. (2012).

governance, empowerment). Yet we know that citizen action leads to such outcomes only in some cases; in others it leads to frustration, and occasionally reprisal (Gaventa and Barrett 2010). Finally, state responses to citizen action are necessary for the desired outcomes, yet it is not clear why officials respond positively in some cases and not others. So what are the steps in the causal chain where the information to citizen action path might break down?
Lieberman et al. (2012) present a fascinating exploration of why a large-scale information campaign to disseminate the results of literacy/numeracy assessments and materials to help children's learning and citizen participation in education in Tanzania had no impacts on citizen action. In their own initial work, a randomised controlled trial of the initiative found no treatment effect for the intervention (i.e. none of the observed citizen participation could be 
attributed to the intervention). To explore the reasons for this finding, they developed an analysis based on expanding the causal chain between information and citizen action. When simple survey and qualitative methods were used to test whether assumptions behind each link in the causal chain held true, they found that only 'a minority - sometimes a very small minority - of the subject population was reasonably likely to advance down any single step of the causal pathway towards increased citizen activism' (Lieberman et al. 2012: 34/35).

Extending this and other work on theories of change (Joshi et al. 2013; Tembo 2012), in Figure 3 I present a series of steps that are required for information to lead to positive state responses. Following Lieberman et al. (2012), each step is posed as a question - for the relevant stakeholder in the process. When the answer to any of the questions is likely to be 'no', then the process of translating information into citizen action faces a roadblock. When the answer is 'yes' then there is a greater chance of the desired outcome (in this case improved service delivery) being achieved. It goes without saying that these questions will have distinct answers in diverse cases. Although the causal chain is depicted here in a linear manner, there may be various leaps in steps and some looping in the chain in particular contexts.

The kind of analysis outlined above, that draws out causal pathways relating specific components of social accountability to each other can be useful in arraying the existing evidence on the impact of social accountability as well as in providing a potential checklist of micro-factors to consider before embarking on particular SA initiatives. The task ahead is to begin a mapping of mini-causal chains and mine existing studies (both qualitative and quantitative) to unearth the assumptions behind each step and the extent to which they seem to hold true more generally. Such work will also point to very simple pilot research for testing assumptions, that could be carried out prior to large-scale implementation of initiatives, and prevent the likelihood of low impacts.

One additional issue needs elaboration. Most studies of impact are looking for the immediate outcomes such as visible improvements in public services. Yet implicit expectations of long-term outcomes are many. As one recent paper put it:
[E]xpected results of social accountability include a reduction in corruption, better governance and policy design, enhanced voice, empowerment and citizenship of marginalized groups, responsiveness of service providers and policy makers to citizens' demands and ultimately the achievement of rights, health and developmental outcomes (Lodenstein $e t$ al. 2013).

These expectations range from immediate shortterm ones to more durable long-term changes within states and societies. Expectations range from those focused on social actors (empowerment, social cohesion, inclusive social norms), to those focused on states (reduced corruption, responsive officials, better policy design, good governance) to those that improve the space where social groups interact with the state (institutionalised channels for participation, increased trust, legitimacy democratic deepening, better policy design) (see Joshi forthcoming). The task then, is to systematically identify all the potential impacts one might be interested in to trace the extent they might have been achieved in specific cases.

An important part of the reason for doing this relates to our view of social accountability as 'an ongoing and collective effort to hold public officials and service providers to account for the provision of public goods which are existing state obligations' (Joshi and Houtzager 2008: 3). If one views social accountability as part of a longer political process of citizen engagement with the state, then histories of prior engagement will shape expectations of stakeholders, expectations that will change over time. This relates closely to the definitions of relevant outcomes and our time frames of assessment: if a social accountability intervention fails in improving services but scores highly on empowerment of citizens, do we consider it a failure or a success, given that the intervention has changed the long-term prospects for accountability by changing the starting point for the next intervention? Whose definitions of outcomes count as they would be different for organic SA initiatives and donor interventions? Tracing a range of intermediate and ultimate outcomes is important for understanding the long causal chain of social accountability work, the impacts that might be achievable and the contextual factors that can influence 'success'. 


\section{Conclusions}

Gurrent social accountability practice has been racing ahead of clear evidence of impact. The paucity of studies of impact (although increasing rapidly), the fragmentation of the data points, the lack of comparative evidence, and the acute shortage of mixed method studies, have all contributed to a situation where there is a strong normative belief in citizen-led accountability without a clear understanding of the conditions under which it can have impact.

Fox (2014) offers a good conceptual start for addressing this, by identifying in an inductive fashion, based on existing studies, several analytical distinctions, lessons from the evidence and new terms to guide further thinking and operational work. From his list, several general ones stand out. There is the overarching distinction between strategic approaches (enabling environments for collective action) and tactical approaches (localised, demand-side, informationbased tools) and the observation that so far most accountability work has been located in the tactical domain. Another one is the appeal to move beyond the local, not just in strengthening state capacity, but also strengthening citizen capacity to make accountability work vertically up - beyond the local. Finally there is the need to not forget democratic electoral accountability and its links with social accountability, as ultimately, the goal is to make the political system work better. These ideas need to be taken up and internalised in operational work.

Central to the debate is the issue of context. As we saw in this article, there are particular challenges to any attempts to identify contextual factors. Foremost, 'context' is a loose term and can relate to any relevant condition. The critical

\section{Notes}

1 By 'initiatives' I mean both: organic citizen initiatives to demand accountability outside formal channels as well as external 'interventions' that aim to foster citizen demand for accountability. I use the term 'intervention' specifically when labelled initiatives such as community scorecards, etc. is meant.

2 www.thefreedictionary.com/context (accessed 7 July 2014).

3 www.macmillandictionary.com/dictionary/ british/context (accessed 7 July 2014). task of course is how to identify which are the 'critical' contextual factors.

A two-pronged approach to the study of context seems to be emerging. On the macro side, and closely aligned to PEA is an approach that examines the existing literature to identify patterns of enabling and constraining contextual factors in broad domains (O’Meally 2013). On the other hand is an approach that attempts to unpack particular causal chains and the microcontextual conditions that seem to make them work. As work on the former is relatively well developed, this article has attempted to develop the latter and start to flesh out some of the issues and challenges that lie ahead.

The approach to context outlined here is distinct from attempting to understand the contextual conditions under which 'labelled' interventions such as community scorecards or social audits work. Focusing on 'labelled' interventions is problematic because most often such interventions are not actually alike in their individual components: rather they share only a broad approach. Instead, by deconstructing the various mini-causal pathways (akin to strands in DNA) and understanding the contextual conditions that make them work, we could potentially recombine the existing evidence to assess the promise of specific existing and new initiatives. In addition, existing initiatives could be assessed for the extent to which they travelled along the causal chain - and where the roadblocks to impact lay. Such an approach also ties in more closely with the more explicitly political and organic analysis suggested in the discussion of macro factors, and is rooted in specificities of the histories and norms of particular contexts.

4 www.oxforddictionaries.com/definition/ english/context (accessed 7 July 2014).

5 By micro-context, I mean the factors often identified in the macro-strategy for their operation at the micro level. This is important because even if the overall climate in a country is favourable for SA-type action, at the local level it might not be. For example, while a country might have a free and fair media, at the local level the newspapers might be controlled by particular groups opposed to greater accountability (see Schultze-Kraft and Morina in this IDS Bulletin). Or particular 
groups/communities may not have access to newspapers, radio or TV, or might be illiterate.

6 Credit for this point and the earlier point about comparative information, goes to the CSO Twaweza (www.twaweza.org), whose thinking in this area was elaborated for me by Varja Lipovsek (pers. comm. 2013).

7 Even work based on such recent advances might be limiting. Some ground-breaking

\section{References}

Aiyar, Y. and Mehta, S.K. (2014) Spectators or Participants? Examining the Effects of Social Audits on Citizen-State Relations and the Local Politics of Corruption in Andhra Pradesh, Accountability Initiative, Engaging Accountability: Working Paper Series, Delhi: Centre for Policy Research

Banerjee, A.; Duflo, E.; Glennerster, R.; Banerji, R. and Khemani, S. (2010) 'Pitfalls of Participatory Programs: Evidence from a Randomized Evaluation of Education in India', American Economic Journal: Economic Policy 2.1: 1-30

Barr, A.; Mugisha, F.; Serneels, P. and Zeitlin, A. (2012) 'Information and Collective Action in the Community Monitoring of Schools: Field and Lab Experimental Evidence from Uganda', unpublished manuscript

Boeckman, S. (2012) Social Accountability in Fragile States Background Paper, Social Accountability Flagship Study, Washington DC: World Bank

Booth, D. (2011) 'Working with the Grain and Swimming Against the Tide', paper for presentation to the panel 'The Politics and Governance of Public Services in Developing Countries', International Research Society for Public Management Conference, Dublin, 11-13 April 2011

Bruns, B.; Filmer, D. and Patrinos, H.A. (2011) Making Schools Work: New Evidence on Accountability Reforms, Washington DC: World Bank

Bukenya, B. and King, S. (2012) The Contextual Factors for Demand-Side Social Accountability, Annotated Bibliography, Social Accountability and Demand for Good Governance Cluster, Washington DC: World Bank

Bukenya, B.; Hickey, S. and King, S. (2012) 'Understanding the Role of Context in Shaping Social Accountability Interventions: Toward an Evidence-Based Approach', Social Accountability and Demand for Good Governance Team Report, Washington DC: World Bank experimental research in diverse populations about societal interactions and rational interest suggests our knowledge of human behaviour is based on studies of cultural 'outlier' populations - W.E.I.R.D. - Western, Educated, Industrialised, Rich, Democratic (Henrich, Heine and Norenzayan 2010). Most of humanity might be operating on other cultural principles.

Cartwright, N. and Munro, E. (2010) 'The Limitations of Randomized Control Trials in Predicting Effectiveness', Journal of Evaluation in Clinical Practice 16: 260-66

DFID (2009) Political Economy Analysis How to Note, DFID Practice Paper, London: Department for International Development

EC/EuropeAid (2008) Addressing Governance in Sector Operations, Draft Reference Document, July 2008, http://ec.europa.eu/europeaid/ infopoint/publications/europeaid/149a_en.htm (accessed 16 June 2014)

Foresti, M.; O’Neil, T. and Hudson, A. (2007) Evaluation of Citizens', Voice and Accountability: Evaluation Framework, London: Overseas Development Institute (ODI)

Fox, J. (2014) 'Social Accountability: What does the Evidence Really Say?', Draft Paper for GPSA, Washington DC: World Bank

Fox, J. (2007) 'The Uncertain Relationship between Transparency and Accountability', Development in Practice 17.4: 663-71

Fritz, V.; Kaiser, K. and Levy, B. (2009) ProblemDriven Governance and Political Economy Analysis: Good Practice Framework, Washington DC: World Bank, PREM Network

Fung, A.; Graham, A. and Weil, D. (2007) Full Disclosure: The Perils and Promise of Transparency, Cambridge: Cambridge University Press Gandhi, J. (forthcoming) 'Literature Review: Social Accountability Mechanisms and their Impact in Closed Polities', Background Paper, Social Accountability Flagship Report, Washington DG: World Bank

Gaventa, J. and Barrett, G. (2010) So What Difference Does it Make? Mapping the Outcomes of Citizen Engagement, IDS Working Paper 348, Brighton: IDS

Henrich, J.; Heine, S.J. and Norenzayan, A. (2010) 'The Weirdest People in the World?', Behavioural and Brain Sciences 33.2/3: 61-135

Holland, J. and Thirkell, A. (2009) Measuring Change and Results in Voice and Accountability 
Work, DFID Working Paper 34, London:

Department for International Development (DFID)

Joshi, A. (forthcoming) On Social Accountability: An Issues Paper, Background Paper for the

Social Accountability Flagship Study, Social

Development Department, Washington DC:

World Bank

Joshi, A. (2013) 'Do they Work? Assessing the

Impact of Transparency and Accountability

Initiatives in Service Delivery', Development

Policy Review 31, Issue Supplement: s1

Joshi, A.; Clark, J.; Hossain, N.; Chopra, D. and

Sabates-Wheeler, R. (2013) The Impact of Social

Accountability Initiatives on Improving the Delivery

of Public Services: A Systematic Review of Four

Intervention Types, Draft Protocol, Brighton: IDS

Joshi, A. and Houtzager, P.P. (2012) 'Widgets or

Watchdogs?', Public Management Review 14.2: 145-62

Joshi, A. and Houtzager, P.P. (2008) 'Introduction: Contours of a Research Project and Early Findings', IDS Bulletin 38.6: 1-9

Khemani, S. (2008) Does Community Monitoring Improve Public Services?' Diverging Evidence from Uganda and India, Research Brief, Human Development and Public Services Research, Washington DC: World Bank

Lieberman, E.; Posner, D. and Tsai, L. (2012) Does Information Lead to More Active Citizenship? An Evaluation of the Impact of the Uwezo Initiative in Kenya, Draft Paper, Dar es Salaam: Twaweza

Lodenstein, E.; Dieleman, M.; Gerretsen, B. and Broerse, J.E. (2013) 'A Realist Synthesis of the Effect of Social Accountability Interventions on Health Service Providers' and Policymakers' Responsiveness', Systematic Reviews 2.1: 98

McGee, R. and Gaventa, J. (2011) Shifting Power? Assessing the Impact of Transparency and Accountability Initiatives, IDS Working Paper 383, Brighton: IDS

Moncrieffe, J. and Luttrell, C. (2005) An Analytical Framework for Understanding the Political Economy of Sectors and Policy Arenas, London: Overseas Development Institute, www.odi.org.uk/fecc/ resources/reports/sector_analysis_framework _odi.pdf (accessed 25 June 2014)

O'Meally, S.C. (2013) Mapping Context for Social Accountability: A Resource Paper, Washington DC: Social Development Department, World Bank
Pandey, P.; Goyal, S. and Sundararaman, V. (2009) 'Community Participation in Public Schools: Impact of Information Campaigns in Three Indian States', Education Economics 17.3: 355-75

Ravallion, M. (2009) 'Evaluation in the Practice of Development', World Bank Research Observer 24.1: 29-54

Reich, Michael and Balarajan, Yarlini (2012) Political Economy Analysis for Food and Nutrition Security, HNP Discussion Paper 76921, Washington DC: World Bank

Ringold, D.; Holla, A.; Koziol, M. and Srinivasan, S. (2012) Citizens and Service Delivery: Assessing the Use of Social Accountability Approaches in Human Development, Washington DC: World Bank

Routley, Laura and Hulme, David (2013) Donors, Development Agencies, and the Use of Political Economy Analysis: Getting to Grips with the Politics of Development, ESID Working Paper 19, University of Manchester

Tembo, F. (2012) Citizen Voice and State Accountability: Towards Theories of Change that Embrace Contextual Dynamics, London: Overseas Development Institute (ODI)

Unsworth, S. and Williams, G. (2011) Using Political Economy Analysis to Improve EU Development Effectiveness, Devco Concept Paper, http://capacity4dev.ec.europa.eu/politicaleconomy/document/using-political-economyanalysis-improve-eu-developmenteffectivenessdraft-0) (accessed 12 April 2013)

Vogel, I. (2012) Review of the Use of 'Theory of Change' in International Development, Review Report, London: Department for International Development (DFID)

Woolcock, M. (2009) Towards a Plurality of Methods in Project Evaluation: A Contextualised Approach to Understanding Impact Trajectories and Efficacy, Brooks World Poverty Institute Working Paper Series 7309, BWPI, University of Manchester World Bank (forthcoming) Opening the Black Box: Contextual Drivers of Social Accountability Effectiveness, Social Accountability Flagship Report, Washington DC: World Bank World Bank (2013) Social Accountability Flagship Study, Draft Concept Note, Washington DC: Social Development Department, World Bank 